\title{
Article \\ Diabetes Capabilities for the Healthcare Workforce Identified via a 3-Staged Modified Delphi Technique
}

\author{
Giuliana Murfet ${ }^{1,2,3, * \mathbb{C}}$, Joan Ostaszkiewicz ${ }^{4}$ and Bodil Rasmussen $1,5,6,7,8$ (D) \\ 1 School of Nursing and Midwifery, Deakin University, 221 Burwood Highway, Burwood, VIC 3125, Australia; \\ bodil.rasmussen@deakin.edu.au \\ 2 Diabetes Centre, Tasmanian Health Service, Burnie, TAS 7250, Australia \\ 3 School of Public Health, University of Technology Sydney, 15 Broadway, Ultimo, NSW 2007, Australia \\ 4 National Aging Research Institute, Royal Melbourne Hospital, Parkville, VIC 3050, Australia; \\ j.ostaszkiewicz@nari.edu.au \\ 5 Centre for Quality and Patient Safety Research, Institute for Health Transformation, Deakin University, \\ 1 Geringhap Street, Geelong, VIC 3220, Australia \\ 6 Western Health Partnership, 176 Furlong Road, St Albans, VIC 3021, Australia \\ 7 Department of Public Health, University of Copenhagen, Nørregade 10, DK-1017 Copenhagen, Denmark \\ 8 Faculty of Health Sciences, University of Southern Denmark, Campusvej 55, DK-5230 Odense, Denmark \\ * Correspondence: giuliana.murfet@ths.tas.gov.au; Tel.: +61-3-6491600
}

check for

updates

Citation: Murfet, G.; Ostaszkiewicz,

J.; Rasmussen, B. Diabetes

Capabilities for the Healthcare

Workforce Identified via a 3-Staged

Modified Delphi Technique. Int. J.

Environ. Res. Public Health 2022, 19,

1012. https://doi.org/10.3390/

ijerph19021012

Academic Editors: Belchin Kostov,

Luis González-de Paz and

Antoni Sisó-Almirall

Received: 17 December 2021

Accepted: 15 January 2022

Published: 17 January 2022

Publisher's Note: MDPI stays neutral with regard to jurisdictional claims in published maps and institutional affiliations.

Copyright: (C) 2022 by the authors. Licensee MDPI, Basel, Switzerland. This article is an open access article distributed under the terms and conditions of the Creative Commons Attribution (CC BY) license (https:// creativecommons.org/licenses/by/ $4.0 /)$.

\begin{abstract}
Consumers access health professionals with varying levels of diabetes-specific knowledge and training, often resulting in conflicting advice. Conflicting health messages lead to consumer disengagement. The study aimed to identify capabilities required by health professionals to deliver diabetes education and care to develop a national consensus capability-based framework to guide their training. A 3-staged modified Delphi technique was used to gain agreement from a purposefully recruited panel of Australian diabetes experts from various disciplines and work settings. The Delphi technique consisted of (Stage I) a semi-structured consultation group and pre-Delphi pilot, (Stage II) a 2-phased online Delphi survey, and (Stage III) a semi-structured focus group and appraisal by health professional regulatory and training organisations. Descriptive statistics and central tendency measures calculated determined quantitative data characteristics and consensus. Content analysis using emergent coding was used for qualitative content. Eighty-four diabetes experts were recruited from nursing and midwifery $(n=60[71 \%])$, allied health $(n=17[20 \%])$, and pharmacy $(n=7[9 \%])$ disciplines. Participant responses identified 7 health professional practice levels requiring differences in diabetes training, 9 capability areas to support care, and 2 to 16 statements attained consensus for each capability-259 in total. Additionally, workforce solutions were identified to expand capacity for diabetes care. The rigorous consultation process led to the design and validation of a Capability Framework for Diabetes Care that addresses workforce enablers identified by the Australian National Diabetes Strategy. It recognises diversity, creating shared understandings of diabetes across health professional disciplines. The findings will inform diabetes policy, practice, education, and research.
\end{abstract}

Keywords: diabetes; healthcare workforce; Delphi technique; capabilities; workforce capacity

\section{Introduction}

Over a quarter of Australians accessing a healthcare service on any given day have diabetes [1,2]. These consumers receive education and care from health professionals with varying levels of diabetes experience in all areas of Australia. However, health professionals' approach to delivering information and the information provided can engage or disengage the person accessing services [3,4]. When health messaging is inconsistent, people living with diabetes tend to disengage from essential health services [3,4]. Reduced access to care by diabetes-competent health professionals increases the risk of preventable costly diabetes-related complications $[5,6]$ that make people living with diabetes retire early, fall into income poverty, and omit care because of the cost, which increases healthcare needs [7]. 
By 2030, diabetes will be the leading cause of health condition burden in Australia [5], when over half of the primarily tertiary-based Credentialled Diabetes Educator ${ }^{\mathrm{TM}}$ (CDE) workforce reaches retirement age [8]. In Australia, CDEs are health professionals who have met the requirements for the title by completing a postgraduate degree in diabetes, 1000 initial hours of diabetes practice, and a 6-months mentorship and have demonstrated ongoing annual participation in professional development within the specialty of diabetes education [9]. A mature and retiring diabetes-trained workforce will reduce the Australian health system's capacity to deliver diabetes care and prevention over the next decade. Hence, to reduce the human and financial burden to people living with diabetes, their families, and the healthcare system, there is a need to ensure that all health workforce members have appropriate knowledge, skills, and attributes to care for them.

The Australian Commonwealth Government and States continue developing policies to fund exponential growth in diabetes-related healthcare needs [10-12]. The Australian National Diabetes Strategy 2021-2030 identified the workforce as an enabler of access to equitable person-focused integrated quality care spanning the health continuum [13].

Internationally, it is recognised that this access will not be sustainable without increasing health professionals' diabetes capabilities [14]. Australian policies to better support diabetes care include Medicare-incentivised models (publicly funded universal healthcare) for general medical practitioners to manage diabetes with generalists, primary healthcare nurses, and allied health professionals in a coordinated manner [10-12]. Driven by policy and employer expectations, primary health professionals must now undertake activities once performed by specialist CDEs $[15,16]$. However, primary healthcare professionals report being ill-prepared to deliver diabetes education without adequate diabetes capabilities internationally and in Australia [14-18].

Australia, like other countries, also has significant complexities and challenges with healthcare delivery, including multiculturalism, which requires that services and information to be tailored appropriately [19-21] and that inequities to healthcare in Indigenous people need to be addressed culturally [22-24]. Further, it is nuanced by geographical areas of significant remoteness [25], where rates of diabetes are high and the duration longer and healthcare access is limited $[23,25,26]$.

Furthermore, the number and complexity of technologies and medicines used to manage diabetes have increased exponentially [27,28], which drive healthcare changes. Australia's areas of remoteness, where extreme shortages of doctors and populations of extreme disadvantage exist $[25,26,29]$, affect healthcare choices available to and made by consumers. For example, despite over a third of Australians with type 1 diabetes residing in areas of increasing remoteness [30], they account for less than $10 \%$ of the total insulin pump usage due to perceived lack of support [31,32]. The broader health professional workforce is not adequately prepared or resourced for these challenges [15,25].

Diabetes care is everyone's business. An imperative exists to develop the future health workforce's capacity to deliver quality primary and preventive diabetes care at a population level. Identifying ways to engage better and meet the diabetes training needs of health professionals working in all settings, particularly rural and very remote areas of Australia, is essential [13].

Competency frameworks are used in many countries to prepare health professionals; they are task-orientated tools that standardise technical skills in stable clinical situations [33]. However, existing competency frameworks designed to equip health professionals with the knowledge, skills, and attributes to provide diabetes care are inadequate [34]. They are unlikely to support the development of the workforce because no diabetes framework in Australia informs the whole workforce, nor are any capability-based. Finally, competency frameworks have little utility in an environment aimed at increasing scope of practice by creating a skilled, flexible, and innovative workforce [35], nor do they recognise the benefits of autonomous practices, which enable innovation [36].

Capability-based learning offers an alternative; while it encompasses competency, it extends beyond technical skills to emphasise the components of adaptability to change, 
lifelong learning, and self-efficacy [35-37]. To expand the workforce's capacity to address future diabetes healthcare needs, understanding the diabetes capabilities required by health professionals is essential. Australia's geographical nuances require a flexible, adaptable diabetes workforce with skills to practice at advanced and extended levels to provide appropriate safe diabetes care $[25,26]$. The current study aimed to develop a consensus capability framework to guide non-medical health professional training and development in delivering diabetes education and care across the Australian healthcare spectrum [34]. The research objectives were to:

1. Identify and understand the different non-medical healthcare professional practice levels used to deliver diabetes care in Australia;

2. Identify the capabilities required to deliver quality, safe diabetes education and care;

3. Increase the health workforce's capacity to manage diabetes.

\section{Materials and Methods}

\subsection{Methodological Approach}

A modified Delphi technique was used to conduct the study, administered in three stages (see Figure 1). The Delphi technique was modified by introducing a pre-Delphi consultation stage to understand workforce development issues better [38]. The Delphi technique offers the advantage of providing a systematic consensus-building methodology to identify healthcare capabilities or priorities [38-40]. It enables a group of 'experts' to explore complex issues and reach a consensus [40], which benefited this study as opinions about roles in diabetes are diverse [41]. Delphi features that ensured information was captured accurately from individual participants were anonymity, eliminating group pressure and the influence of dominant personalities, iterations reviews with controlled feedback, and quantified ranking of group responses [38,40].

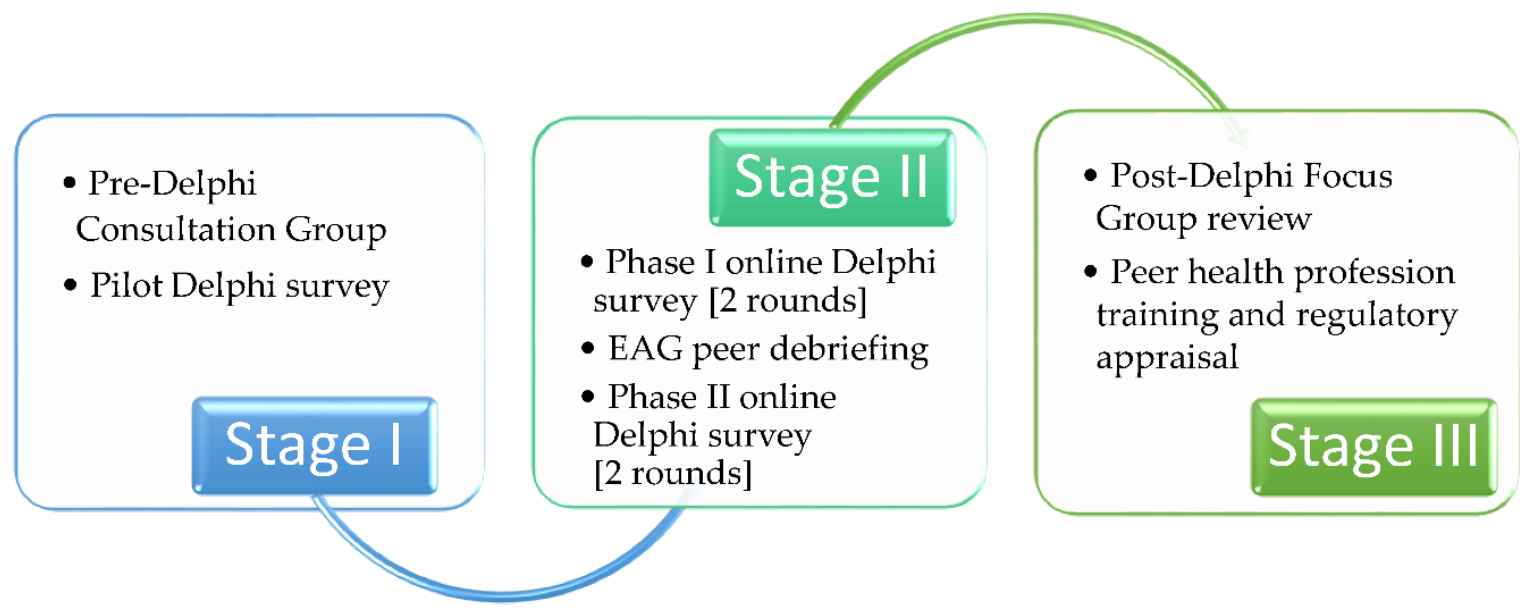

Figure 1. Stages for modified Delphi technique.

\subsection{Theoretical Framework}

Several theories underpinned the study and the development of the capability framework structure. The framework's focus was to increase workforce capacity in diabetes by guiding training for a flexible workforce. Theories were divided into three categories: clinical competence, expertise, and capability. Benner's stages of clinical competence, Ericsson's theory of expertise, and Sen's capability approach theory were used as the theoretical framework to guide the research [42-44].

\subsection{Research Characteristics and Reflexivity}

As an instrument within the research process that can profoundly affect the research [45], G.M. describes her experiences that could have influenced the study in unknown ways. As a Nurse Practitioner and CDE with 30-years' experience in clinical and 
management settings, G.M. has supported people who live with diabetes through assessment, diagnosis, prescribing, education, and research. G.M. has held leadership positions nationally as Board Director of the Australian Diabetes Educators Association (ADEA) that credentials diabetes educators and Diabetes Australia, a consumer advocacy organisation. G.M. approved the ADEA Indigenous Educational Pathways Project, among other projects. G.M. has represented diabetes and nursing nationally at Ministerial advisory groups and Government-funded Pharmaceutical Benefits Scheme reviews. The current study's focus fitted with G.M's keen interest for equitable access to high standards of safe quality care, regardless of the healthcare setting and consumer needs.

\subsection{Setting}

The setting was the Australian health system. The sampling population was nurses, midwives, pharmacists, and allied health professionals employed to deliver diabetes education and care with people living with diabetes in a clinical, management, or educational role. Additionally, academics in diabetes workforce training, research, and professional development were involved.

\subsection{Sampling Strategy}

A heterogeneous and representative sample was recruited by applying the proportions of health disciplines established through the ADEA 2017 member survey [8]. Seven health discipline organisations advertised the study openly via member communications to reduce bias, which included a Plain Language Statement.

The expert Delphi participants were recruited over 11 weeks by a combination of purposeful and snowballing sampling approaches. Data saturation was monitored to ensure an adequate sample size [46]. Recruitment stopped when participants' feedback provided no new insights.

Benner's theoretical stages of clinical competence, which has been validated in various adult learning settings with different disciplines [42], and Ericsson's theory of expertise, which recognises the importance of routine deliberate practice [43], informed the inclusion criteria-to ensure sampling from expert diabetes health professionals and academics from various disciplines who deliver care, lectures or research in diabetes. Health professionals required more than five years post-registration experience and to be either:

- $\quad$ A CDE for five years or more;

- In a position whose focus of employment for the past five years or more was diabetes education and care or/and research.

\subsection{Ethical Considerations}

No participants' names were recorded or was identifiable information shared to maintain confidentiality. A password-protected computer, survey platform, and email address were used to conduct the survey. Data exported to Excel was stored on Deakin University's system, offering high-level security and anti-virus programs to maintain data integrity. Data will be destroyed after five years, following Deakin policy.

\subsection{Data Collection Methods}

Various data collection methods were used in the Delphi technique, which informed sequential steps. See Figure 2 for the chronology of the data collection methods. 


\begin{tabular}{|c|c|}
\hline $\begin{array}{l}\text { Literature review about capabilities } \\
\text { and competencies for diabetes } \\
\text { education and the workforce. } \\
\text { Formation of research questions } \\
\text { and conceptualising proposed } \\
\text { framework. }\end{array}$ & $\begin{array}{c}\text { STAGE I: Pre-Delphi Consultation } \\
\text { Applied for and gained Ethics Approval. } \\
\text { An advertisement was forwarded to ADEA members via email. } \\
\text { Conducted Consultation Group in 2018 aimed to verify issues } \\
\text { impacting diabetes workforce development and identify valuable } \\
\text { information to inform the Delphi survey questions and enhance the } \\
\text { framework } \\
\text { Pilot test of Qualtrics platform and Delphi survey. }\end{array}$ \\
\hline & \\
\hline $\begin{array}{l}\text { STAGE II: Recruitment Phase } \\
\text { Experts identified via research criteria and } \\
\text { invited to participate. Plain Language } \\
\text { Statement and online survey link forward to } \\
\text { interested participants. } \\
\text { A recruitment target of } 60 \text { participants was } \\
\text { set to capture diverse disciplines. }\end{array}$ & $\begin{array}{l}\text { STAGE II: Delphi survey } \\
\text { The Delphi survey consisted of two phases, each with two } \\
\text { rounds of questionnaires. Each round was open for 4- } \\
\text { weeks and provided participants with a summary of the } \\
\text { previous round's outcomes. A weekly reminder and two } \\
\text { days before survey closure was set up in Qualtrics for } \\
\text { non-responders and incomplete questionnaires. }\end{array}$ \\
\hline
\end{tabular}

\section{V}

STAGE II: Delphi Survey Phase 1 (Round 1)

Initial questionnaire consisting of three sections:

(1) a brief overview of the Delphi technique,

(2) demographic questions,

(3) three open-ended questions asking participants about existing health professional practice levels, the basic or fundamental and advanced knowledge, skills and attitudes (KSA) required by health professionals to provide diabetes care and diabetes medicine management.
STAGE II: Content analysis

Analysis of data for categories and repetition, and the language of the expert panel to identify health professional practice levels.

Models identified to be reduced to 4-6 and tested with EAG.

Six EAG consensus meetings were held across all analysis periods.

\section{STAGE II: Delphi Survey Phase 1 (Round 2) \\ A second questionnaire consisting of: (1) a summary of expert panel comments and (2) 4-6 models to describe the Framework's structure for preferred ranking between 1 (preferred) to 4 . \\ A third questionnaire if required for ranking. \\ Stages of clinical competence linked to practice levels, then finalised with EAG. The model achieving consensus for the Framework shared with the panel. Consensus of model for framework}

\section{STAGE II: Delphi survey Phase 2 - Identification of Capabilities and statements}

Content analysis of KSA for diabetes education and medicine management identified in Phase 1, Round 1. Major categories identifies broad capabilities and sub-categories identifies capability statements.

Peer debriefing and member validation by Expert Advisory Group.

Confirm the appropriateness of capability statements' position and recommend any omissions.

\section{STAGE II: Delphi Survey Phase 2 (Round 1)}

Initial questionnaire presenting (1) a summary of analysis process and (2) the capability statements, listed under each of the practice levels that gained consensus and relevant capability identified during analysis.

Panel invited to rank importance of each statement on a 5-point Likert scale: 1 (not important) to 5 (essential).

\section{STAGE II: Delphi Survey Phase 2 (Round 2)}

A second questionnaire consisting (1) a summary of Delphi panel comments and (2) capability statements that did not reach consensus but achieved $>40 \%$. Panel invited to rank these again.

A third questionnaire if required for ranking.

Draft Capability Framework finalised

$$
\text { V }
$$

\section{STAGE III: Stakeholder Consultation}

Recruitment and process mimicked that used in Stage I. Draft Capability Framework forward for appraisal to:

1. Focus Group at the 2019 national diabetes conference; the information gathered informed the final draft. Furthermore, participants reviewed the final 22 capability components that had not achieved consensus via the Delphi survey.

2. Health professional peer and training organisations relevant to disciplines involved in study. Sixteen Australian educational organisations providing training for Certificate III and IV health provider roles, undergraduate nurses and allied

$\rightarrow \begin{gathered}\text { Finalise framework } \\ \text { Consensus } \\ \text { Capability } \\ \text { Framework } \\ \text { Dissemination of } \\ \text { results }\end{gathered}$

health, and postgraduate diabetes degrees and 16 peer organisations from

disciplines eligible for CDE status were invited to appraise framework via a survey.

Figure 2. Flow chart guiding chronology of data collection methods. 


\subsubsection{Stage I}

Pre-Delphi semi-structured consultation group

The purpose of the pre-Delphi consultation group was to understand issues impacting diabetes workforce development. It was limited to 20 participants to collect quality dialogue and diverse opinions [47,48]. An advertisement including a SurveyMonkey link captured demographic data to ensure inclusion criteria and adequate breadth of disciplines were met.

An independent, experienced moderator led the audiotaped semi-structured discussion. The moderator followed a protocol, which included seven guiding questions regarding workforce issues, differences in health professional diabetes training and skills requirements, and risks, benefits, and barriers to non-medical prescribing. G.M. took contextual notes regarding the environment, participant engagement, and body language and summarised emerging issues from the conversation. Summaries were fed-back verbally at intervals during the discussion to ensure the interpretation was correct. Finally, the audiotape was transcribed verbatim.

Pre-Delphi pilot

The purpose of the pilot was to establish whether respondents interpreted the questions and instructions as intended, to test the features of Qualtrics', the web-based platform, and to estimate the time taken to enhance the questionnaire's face and content validity and trustworthiness. Seven purposefully sampled diverse diabetes experts participated, and Qualtrics was used to forward the questionnaire via email. Their feedback guided the amendments to features implemented to enable flexibility to support engagement. Next, Stage II commenced.

\subsubsection{Stage II}

The purpose of Stage II was to address the study's research questions and gain consensus on different framework aspects.

Expert Advisory Group: Stage II and III were guided by five independent researchers to support the validation and trustworthiness of results at data analysis points and ensure:

- No capability components were overlooked;

- Capabilities identified would allow workforce capacity growth;

- The volume of data collected during each method was managed;

- An accurate model describing practice levels was chosen.

The EAG members held expertise in qualitative and Delphi research, pregnancy, technology, emotional health, prescribing, and course development. They were all national leaders in diabetes education and care and research from nursing, dietetics, midwifery, and behavioural science (see Table S1). The EAG provided objective evaluations through peer-debriefing and technical and explanatory guidance; consensus regarding analyses was based on the majority.

Delphi survey Phase one: The purpose of Phase one was to identify the health professional practice levels signifying a change in diabetes knowledge and skills required. An online questionnaire was emailed to participants, asking demographic characteristics and three focused questions (see Figure 2). Following analyses and EAG appraisal and consensus, a second-round questionnaire presented participants with four models describing different diabetes practice levels [34]. The four models' focuses were: (i) nursing only, (ii) Government-registered health professionals only, (iii) multidisciplinary, and (iv) worksetting, i.e., tertiary, secondary, primary, and remote. Participants were invited to rank their preferred model from 1 (preferred) to 4 (least preferred).

Delphi survey Phase two: The purpose of Phase two was to identify the essential capabilities required for diabetes care and reach a consensus about the alignment of specific capability components for each diabetes practice level (see Figure 2) [34]. Following analyses and EAG peer review and consensus, participants were emailed a questionnaire with 2 to 16 capability components under each diabetes practice level. Following further analyses and EAG appraisal, the second-round questionnaire included a summary and the capability components that had not reached consensus. Participants were invited to re-rank 
the statements. Next, a draft Capability Framework for Diabetes Care ('Capability Framework') was prepared and confirmed by the EAG in preparation for Stage III.

\subsubsection{Stage III}

Focus group: In Stage III, a focus group was convened to validate the draft 'Capability Framework' to ensure the information gathered was well-grounded and transferable to the real world. The group was smaller, as four to six participants maintained higher communication quality levels better for brainstorming [45]. The 'Capability Framework' was appraised for completeness and practicality and to identify limitations or gaps against the study's aims [47]. Following minor amendments and EAG review, the draft framework was forwarded for stakeholder appraisal (see Figure 2).

Stakeholder appraisal and feedback: The final data collection activity was a stakeholder consultation to identify any issues impeding practice or safety and determine whether the 'Capability Framework' addressed the Australian National Diabetes Strategy 2021-2030 [13]. Sixteen Australian educational organisations were invited to appraise and provide feedback about the framework via a survey. The survey was open for 4 weeks on Qualtrics or hard copy. Questions focused on identifying whether the framework was easy to navigate and on clarifying whether any capability impeded practice or could impact safe practice.

\subsection{Data Analysis}

Each data collection method informed the next; qualitative and quantitative data were collected.

\subsubsection{Qualitative Data Analysis}

Content analyses were used to identify, analyse, categorise, and report patterns within qualitative data throughout the Delphi stages [49]. The study used an inductive approach and emergent coding to manage issues [50]. The following coding rules were applied before content analysis to maintain rigor, as coding is a reflective process [49]:

- The level of analysis used was word sense, phrase, or sentences of similar meanings;

- Flexibility in the coding process with no predefined number or list of concepts;

- Concepts would be coded for their content, not frequency;

- Concepts would be developed to align with study questions and aims as they emerged into categories.

G.M. established categories and sub-categories following the preliminary data examination after repeated listening to audio recordings and reading verbatim transcripts [50]. Word clouds identified the diabetes experts' language used to inform titles and categories to reduce researcher impact. Repetition of similar words or meanings enabled data saturation to be achieved/identified. Key reoccurring sub-categories were appraised by T.D. and J.O. for accuracy. Then, G.M. reported on categories and patterns to the EAG, who cross-checked emerging categories for accuracy, relevancy, applicability, duplication, or need for further condensing. In Delphi survey Phase one, practice levels were defined, and a stage of diabetes clinical competence derived from participants words was allocated. Next, capabilities were given a definition, and their components were finalised, assessed against study aims, and critically reviewed until consensus was achieved.

\subsubsection{Quantitative Data Analyses}

Descriptive statistics and measures of central tendency were calculated to describe the proportions of categorical variables, such as participants' demographic characteristics and the response rate for each Delphi technique stage and preferred positioning. The definition of consensus for ranked data was: $\geq 75 \%$ accumulative votes within two more favourable (retained) or least favourable (rejected) categories on the 4-point polling and a mean of $\leq 1.75$ or $\geq 3.5$ on the 5-point Likert scale.

When opinions were broad, e.g., medicines capability, variances and SDs were affected by extremely high or low values on the 5-point Likert scale; central tendency measures did 
not capture where the majority sat on the topic [51]. Hence, the mean absolute deviation from the median (MADM) was calculated to measure participant disagreement and data spread, ignoring data outside of a trend [51]. The level of agreement was categorised into MADM thirds (low $>0.75$, moderate $0.48-0.75$, high $<0.48$ ) - the average distance of participants' ratings from the group's median rating [51]. For items ranked according to medians; 4-5 was defined as strong, 3-3.5 as moderate, and 1-2.5 as weak support.

\subsubsection{Techniques to Enhance Trustworthiness}

Triangulation helped produce more comprehensive findings by integrating information and perspectives from different sources and approaches, which were conferred with the EAG to overcome qualitative research's intrinsic biases [52]. Approaches applied to check the meaning of the data generated from the study included reflexivity, peer-debrief, cross-coding, audit trail, and reflective journaling. Researchers regularly evaluated data collection methods on two composite processes: fidelity to the subject matter and utility in achieving research goals [53].

\section{Results}

Eighty-four expert diabetes health professionals participated in the study. The majority were registered nurses $(n=60[71 \%])$, ten of whom held midwifery qualifications, and the remainder were pharmacists $(n=7$ [9\%]) and allied health professionals $(n=17[20 \%])$ (see Table S2). These experts resided in all Australian areas of remoteness and represented various healthcare sectors, including primary care, tertiary care, and academia.

\subsection{STAGE I: Pre-Delphi Consultation}

\subsubsection{Findings to Inform the Framework}

Self-regulating scope of practice: Findings supported the need to explore further the scope of practice of diabetes educators and the different disciplines eligible for credentialling as a CDE [34]. Participants expressed concerns about the challenges associated with autonomous decision-making by individual health professionals for determining personal scope of practice. Participants indicated that the lack of clarity about scope of practice among diabetes educators from different disciplines created:

- Difficulties in identifying role boundary delineation between disciplines;

- $\quad$ Potential unsafe practices in diabetes care.

Many participants indicated that the exposure and training accessed by the health professional might not be adequate to provide safe care in certain circumstances when the expansion of scope is driven by health service needs rather than the individual's skills or the wishes of consumers.

Access to quality mentoring: Findings suggested the need to incorporate a mechanism for ongoing mentoring in diverse diabetes areas [34]. Participants expressed concern about access to and quality of mentoring and indicated that access to the diversity of diabetes care is imperative. Most participants attributed differences in diabetes capabilities to the individual health professional's access to lifelong mentorship in diabetes. Moreover, participants suggested deficits in competence derived from narrow mentorship. Participants described 'narrow mentorship' as relating to the mentors' skills, knowledge, and exposure, whose experience may be limited to one diabetes population.

\subsubsection{Findings to Inform the Delphi Survey}

The findings suggested that scope of practice, medicine management and non-medical prescribing, and diversity and training among health disciplines required exploration in the survey [34].

\subsubsection{Findings for Policy Advice}

Drugs and Poisons Legislation and terminology used: Findings confirmed the need to improve consistency across Drug and Poisons Legislation about how health professionals 
can be involved in medicine management. Participants expressed concerns about the lack of consistency between Australian States and Territories legislation, which hampered mentoring. Often this related to improved clarity about the medicine management practices non-medical health professionals can support or amendments to medications once prescribed. Participants recommended consistency in legislation nationwide.

Non-medical prescribing supporting healthcare access: Findings suggest non-medical prescribing is a workforce solution. Participants expressed that non-medical prescribing by health professionals knowledgeable about diabetes management and medicine could support an appropriate increase in, and timely access to, healthcare. They recommended considering an advanced level of CDE with a limited prescribing endorsement to increase capacity.

Remuneration for private sector CDEs: Findings suggest that the private sector CDE workforce, including nurse practitioners, requires improved Government remuneration to enable viable business models. Participants reported discrepancies in remuneration for disciplines providing diabetes education and care. They indicated that these inconsistencies prevented working full-time in private practice because a business would not be viable. Moreover, funding impediments hampered the growth of the diabetes workforce, which did not allow for private diabetes educator workforce growth to meet primary care needs [34].

\subsection{STAGE 2: Delphi Survey}

\subsubsection{Delphi Survey Phase I Findings}

The response rate was high: $88 \%$ and $91.7 \%$ across the two rounds (see Figure S1). Analyses of Phase one responses and EAG consensus identified four models to describe health professional practice levels. Model 3 (multidisciplinary) and Model 4 (work-setting focus) had smaller SDs and variances than the other models, suggesting more congruency in positioning. Model 3 had the lowest mean of 1.95 (SD 0.81, variance 0.65 ) and an accumulative ranking of $79 \%$ when the two preferred positions were calculated and accepted as the consensus preferred model. Model 4 had the highest mean of 3.33 (SD 0.88, variance 0.78) and an accumulative ranking of $86 \%$ in the two least preferred positions. Model 1 achieved a mean of $56 \%$ and Model 2 a mean of $51.1 \%$ and larger variances (see Table S3).

The multidisciplinary model included seven health professional diabetes practice levels within the workforce requiring a difference in diabetes training (see Figure S2) and aligned to a stage of diabetes clinical competence from foundational to master (see Table S4). Practice levels one to three were generalist roles, and four to seven were diabetesspecific roles.

\subsubsection{Delphi Survey Phase 2 Findings}

The response rate remained high across the two Delphi survey rounds: $83 \%$ and $80.4 \%$ (see Figure S1). Analysis and EAG consensus of participants' responses about the knowledge, skills, and attributes carried over to Phase two identified nine capabilities required to deliver diabetes education and care (see Table 1). Notably, the capabilities differed in focus; practice levels one to three emphasised awareness and promotion, and levels four to seven exemplified adept advanced diabetes skills (see Table 1).

The analyses also identified three groupings of attributes that underpinned the diabetes capabilities required by health professionals (see Table S5): attributes to support excellent communication, collaboration, and advocacy; strive for excellence; and ensure the professional's health and wellbeing to enable adaptability in dynamic environments. 
Table 1. Nine capabilities required to deliver and support diabetes care and their definition.

Diabetes capabilities for practice levels one to three. The capabilities focus on awareness or promotion and are defined as: Displays clinical assessment capacities: demonstrates foundational skills and is developing clinical assessment skills relevant to diabetes to assist with diagnosis and care and identify health status changes.

Supports diabetes self-management education: promotes, assists, and encourages self-management considering the needs, goals, and life experiences of the person with diabetes using teaching skills and a structured decision-making process guided by evidence and an understanding of health literacy.

Builds therapeutic relationships: develops intentional connections focused on person-centeredness and shared decision-making between a healthcare professional and an individual requiring diabetes support; the positive relationship engaged for effecting a beneficial change towards an individual's goal.

Communicates with influence: informs with the intention to affect behaviour change; to inspire, motivate, encourage, guide, and advocate for people living with diabetes or prediabetes.

Supports counselling to achieve the best outcomes: uses supportive counselling techniques within an empowerment framework when guidance on actions is required and identifies mental health issues in people living with diabetes, such as diabetes-related distress or burnout and depression.

Supports quality use of medicines (QUM): demonstrates QUMs in a supportive role and identifies potential medicine-related risks and benefits.

Displays quality use of diabetes technology: demonstrates a supportive role with individuals using technology and identifies potential risks.

Supports care coordination: assists in care coordination and transition as directed or is involved in developing and implementing a care plan for the management of diabetes and facilitates appropriate services in conjunction with a medical team.

Achieves quality: displays a supportive role within quality and research activities and incorporates evidence in all practice elements.

Diabetes capabilities for practice levels four to seven. The capabilities focus on diabetes healthcare professionals who work at an advanced practice level and possess adept diabetes skills in diabetes care and education, and the capabilities are defined as:

Exemplifies clinical assessment capacities: advanced assessment skills and knowledge, clinical acumen, and reflection in and on practice to enable more comprehensive and individualised assessment for the person with complex diabetes issues and accumulative comorbidities.

Shapes diabetes self-management education (DSME), support and care: competent to design, implement, deliver, and evaluate structured DSME. Influences the continuous development of improved diabetes care skills in consumers and practices to optimise DSME, support, and care. Innovative and leads changes; promotes and develops processes to support improvement in health literacy.

Builds therapeutic relationships: adept at developing positive relationships between healthcare professionals and individuals requiring diabetes support through structured shared decision-making. Mentors others and incorporates evidence into local protocols, guidelines, and the organisation to better engage with people living with diabetes and their carers and effect beneficial change.

Communicates with influence and leadership: proficient at communicating with the intention to achieve an effect: to listen, inspire, motivate, and encourage both the consumer and other healthcare professionals. Leads with purpose and promotes wide-reaching advocacy for people living with diabetes.

Exemplifies counselling to achieve the best outcomes: adept at using supportive and empowering counselling techniques and implements significant evidence into guidelines, protocols, and the organisation. Proficient at detecting mental health issues early, such as diabetes-related distress, diabetes burnout, and depression.

Exemplifies quality use of diabetes technology: proficient or regarded as an expert at teaching, operating, and monitoring diabetes technology via different processes, i.e., providing self-management education, technology advice and care, and, in some cases, prescribing if the device administers a medicine.

Exemplifies QUMs: proficient or regarded as an expert at ensuring diabetes medicines are used safely when needed. Delivers comprehensive medicines management, including essential elements such as rigorous monitoring and de-prescribing when indicated.

Leads care coordination: adeptly coordinates relevant stakeholders involved in the consumer's care to deliver appropriate healthcare services promptly and efficiently. Aware of the specific requirements of vulnerable groups and people with complex diabetes issues and monitors and evaluates outcomes.

Cultivates quality through leadership and research: identifies, engages in, mentors, and leads research and quality and safety improvement activities to identify ways to improve diabetes education and care. 
Overall, 257 capability statements were accepted in Round one. All statements listed under practice levels four to seven reached a consensus. Five statements reached $74 \%$ and were also accepted (see Table S6 for ranking scores). Twenty-eight statements did not reach consensus derived from practice levels one to three and were neither accepted nor rejected. The strength of agreement was high, i.e., MADM $<48$ for most capability statements in practice levels four to seven. However, there was more disagreement related to capability statements for practice levels one to three in the following capabilities: clinical assessment capacities, DSME, counselling, technology, and QUM, where the strength of agreement was low, i.e., MADM >75 (see Table S6).

In Round two, six capability statements gained consensus; four were accepted, one was rejected, and following MADM calculations, one was removed from the list based on the strength of disagreement. The last 22 capability statements carried over to Stage III.

\subsection{STAGE III: Post-Delphi External Appraisal}

Focus group participants accepted nine capability components and twelve more after altering the emphasis to 'awareness' or 'promoting' the issue to prompt action, and one was rejected. Participants encouraged the addition of Pharmacy Assistants and requested a capability component relating to disability, added in practice level one. They identified how colleges and universities could use the framework for training and how employers could use the framework to identify skill mix requirements. They emphasised that it was not a job description but a platform to guide training to better care for people with diabetes.

External health profession appraisal was largely favourable from the ten responders $(31.3 \%)$. The majority indicated that the 'Capability Framework' would support developing a competent, flexible, and adaptive workforce for diabetes care and would not impede practice. Advice included adding the midwife more frequently and reconsidering the term generalist to prevent impeding practice. Most indicated the framework would not lead to unsafe practice; however, they advised reconsideration of an unrealistic medicine capability for healthcare assistants. Following EAG amendment advice and consensus, the Capability Framework for Diabetes Care was finalised (see the final allocation of roles in Table S7).

\section{Discussion}

The findings have both workforce and policy implications that can increase capacity within the workforce for diabetes care if adapted.

\subsection{Workforce Implications}

\subsubsection{Workforce Diabetes Health Literacy and Preparedness for Diabetes Care}

To be enabling, health environments and the workforce must be health literate-explicitly to support people living with a chronic condition due to the complexity and fragmentation of the healthcare system and health professionals' impact on consumer health literacy $[3,54]$. The study highlighted the importance of a diabetes health literate workforce to build capacity and identified a guiding 'Capability Framework' [34]. Increasing workforce capabilities in diabetes care will increase the capacity for helping consumers to understand, appraise, and apply information to motivate and make effective decisions [55]. Currently, the health workforce cannot adequately support diabetes health literacy.

Outcomes of the Diabetes Care Project study, a Medicare-incentivised model, suggest that primary care nurses and allied health professionals' skills and competence in managing diabetes currently may be inadequate to individualise diabetes care to support extensive clinical change [10]. The reduced primary endpoint $\mathrm{HbA} 1 \mathrm{c}$ by $0.2 \%$, although statistically significant in the study's 5-point intervention group, was not clinically significant [56]. Similarly, a systematic review of international literature suggests that generalist/primary care health professionals lack confidence in knowledge and skills to individualise care and affect major changes in diabetes outcomes [14].

One reason for the lack of preparedness of the healthcare workforce for diabetes care may relate to health professional undergraduate courses. A national review of education 
about diabetes in undergraduate Bachelor of Nursing programs found Australian universities provided 4 to $21 \mathrm{~h}(0.5-2.5 \%)$ of diabetes-specific teaching across subjects [57]. Moreover, undergraduate students' exposure to diabetes management during clinical practice varied, and the quantity was unmonitored [57]. Therefore, undergraduate health degrees may have inadequate diabetes content. Curricula require guidance about the level of knowledge and skills needed to improve health professional diabetes literacy and consistency, promoting consumer engagement [3,4].

A mismatch between priorities exists given the daily prevalence of people with diabetes accessing healthcare services in Australia [1] and diabetes' national health priority status [13]. Without plans to assess or accredit undergraduate nurse courses regarding diabetes content [57], there is little prospect for a diabetes health-literate workforce [55]. It is unclear whether other professions' undergraduate degrees have adequate diabetes content. National priorities are identified to create change to improve health outcomes; the 'Capability Framework' can guide relevant course content to support the priority. The 'Capability Framework' promotes a knowledgeable, compassionate health workforce, where, as a caring workforce, discussions about or with people living with diabetes is neither demeaning nor stigmatising, fostering engagement $[3,4]$.

\subsubsection{Capability Framework for Diabetes Education and Care}

The 'Capability Framework' guides the training of health professionals nationally. It uniquely supports whole workforce growth in diabetes consistently and creates shared understandings between disciplines. Moreover, the framework's strength is its emphasis on capability-based learning, which focuses on outcomes $[44,58,59]$, compared with existing competency-based diabetes frameworks. Rather than merely fulfilling the minimum requirements of a role, health professionals are encouraged to go beyond to reflect on learnt skills.

A recent American study using a 5-round modified-Delphi technique identified 130 competencies across six domains that align with the capability areas of the current study: clinical management practice and integration, communication and advocacy, personcentred care and counselling, research and quality improvement, systems-based practice, and professional practice [60]. Similarly, the competencies were intended to guide practice regardless of discipline; however, competencies were presented as health areas, e.g., healthy eating, for the Diabetes Care and Education Specialists only and not the broader health workforce, reducing adaptability and consistency across the workforce. The study also used a substantial sample-457 participants-which creates data analysis challenges to ensure accurate interpretation [40]. Furthermore, the final product was not validated with 'real users'; the last Delphi appraisal rounds were not independent.

Competency frameworks' ties to one-dimensional views of learning, healthcare roles, and discipline requirements create limitations in a dynamic health system [58]. Moreover, national and international diabetes competency frameworks often focus on individual health topic areas or one health professional discipline [34,61-65], reducing flexibility and consistency in training and language across disciplines.

The findings from the current study are important because the application of Sen's capability approach to the education setting has been found to increase flexibility and responsiveness, translating to increased workforce capacity [59]. Sen's capability approach is a personal utilitarian approach with two specific elements: functioning and agency [66]. From an agency perspective, individuals feel happiest and perform the best when they are more satisfied by pursuing goals they value $[59,66]$. Combining Sen's theory with career educational development approaches can create opportunity and increase capacity drawn from agency [44]. Promoting the concept of agency in education can educate health professionals to reason on personal decisions and preferences, enhance their capacities to reflect critically on their surroundings and work environment, envisage changes, and cultivate capacities to realise such changes in practice [66]. 
Evidence suggests that competence derives from a functional sphere-the functional facility to solve complex problems that turn a series of elements such as knowledge and skills into competencies, whereas capabilities derive from an ethical and normative spherethe opportunity to choose an action, choice, or behaviour [66]. Thus, the capability approach is broader and not demand-orientated; health professionals are guided by the freedom to choose and develop, thus giving rise to autonomy $[44,66]$. Consistent with Sen's capability approach, the framework promotes self-efficacy, focusing on health professionals' capabilities and enabling targeted education as evidence evolves, leading to increased workforce capacity [59].

Real-time learning fosters the health professional's ability to adapt to clinical situations [58]. Given this, making the 'Capability Framework' an online and 'living' framework has merit because it can be updated as evidence evolves, which aligns with the Australian National Diabetes Strategy that recognised the need for increased preparedness [13]. A 'living' framework creates an opportunity to enable increased workforce adaptability, including accelerating change when faced with emerging public health challenges.

The 'Capability Framework' promotes multidisciplinary diabetes credentialling and recognises diversity through including diverse disciplines in the diabetes practice levels, increasing the capacity for diabetes care in the workforce. The 'Capability Framework' assists workforce planning when used as a tool to identify staff working at each practice level in an organisation or region, thereby identifying workforce gaps. Furthermore, it can support capacity-building by integrating different disciplines and expertise within diabetes teams, guiding more comprehensive diabetes assessment and care.

A limitation of multiple frameworks, as used in the United Kingdom and Australia, to guide different disciplines in diabetes is inconsistency in training across professions [9,61-64] Moreover, there is a risk of reduced relevancy because diverse organisations' priorities drive ongoing reviews. Discipline-specific competency-based training might not enable expertise because of the ties to specific workplace healthcare roles and discipline requirements rather than accommodating for the dynamic changes in healthcare and the person with diabetes needs [58]. Thus, diversity in diabetes teams combined with capability-based training can promote more in-depth clinical reasoning using cross-discipline learning. The 'Capability Framework' sets standards for diabetes education and care, which could, in turn, reduce role boundary confusion by clearly identifying the requirements and capabilities for diabetes education courses.

\subsubsection{Mentoring and Practice}

The findings suggest that lifelong quality mentoring is critical to improving practice and that the geographic maldistribution of different health professionals impacts their access to quality diabetes mentoring [34]. An approach is required to support quality mentoring and stronger links between newly graduated and generalists with diabetescompetent health professionals to build the capacity for diabetes care within the healthcare workforce [15-18]. Moreover, access to two-way mentoring relationships between Aboriginal health workers and non-Indigenous health professionals is needed to promote healthcare access equality in Australia [67]. Internationally as in Australia, significant disparities in Indigenous populations' socioeconomic status and environmental contexts inextricably result from past and contemporary colonialism policies and practices that continue to drive inequities that have persisted for generations [23,24,67]. Mentorship and working with Indigenous health workers can reduce fear in the Indigenous person accessing care and promote safe cultural practices $[23,24,67,68]$.

The 'Capability Framework' can guide both mentoring and clinical practice. Ericsson identified that the acquisition of expert performance comes from ongoing training, mentoring by others, and reflection in and on practice to improve approaches to undertaking an activity [43]. To move towards expertise, Benner's stages of clinical competence suggest that the health professional moves through stages where concepts are tested [42]. Combining 
these theories created a framework to ensure more health professionals develop expertise in diabetes to meet consumer needs.

As with other countries, barriers exist in Australia, nuanced by remoteness, poor dispersion, and access to suitable mentors. Therefore, the 'Capability Framework' requires the addition of a mechanism or technology to allow remote and rural CDEs to access quality mentors routinely to build capacity in diabetes care.

\subsection{Policy Implications}

\subsubsection{Medicine Management in Diabetes Care}

The 'Capability Framework' provides policy and guidance for organisations about how health professionals at different practice levels can support medicine management. Further, it articulates a structure to describe a career pathway for diabetes educators to increase their scope of practice into non-medical prescribing. However, only nurse practitioners can prescribe, and appropriately endorsed podiatrists and pharmacists, who may be a $\mathrm{CDE}$, have limited prescribing rights in Australia. Therefore, consideration should be given to developing an appropriately trained advanced-level CDE role focused on complex care, with prescribing endorsement against a glucose-lowering formulary as a workforce solution to increase capacity for diabetes care.

Developing diabetes medicine management capabilities within the health workforce is crucial, primarily due to high rates of poor diabetes medicine adherence and increasing morbidity and mortality $[68,69]$. A recent study following 1.2 million Australians living with type 2 diabetes found inequities; those residing in remote or disadvantaged socioeconomic groups were less likely to access newer medicines with cardiovascular benefits than those in metropolitan areas [70].

Promoting medicine management capabilities and non-medical prescribing has increased access to appropriate care, which has produced economic benefits and improved patient outcomes [39]. Findings suggest CDEs already work collaboratively with medical officers who often seek their advice on diabetes medicine-an underutilised expert resource with current knowledge about glucose-lowering medicines [34]. Identifying a means for supporting non-medical prescribing capabilities using experienced and skilled CDEs could promote increased care in remote areas.

However, the study revealed that CDEs do not share an understanding of how they should be involved in medicine management because of the profession's multidisciplinary nature and multiple legislation [34]. The lack of shared understanding creates confusion, differences in practices and what the consumer can expect to receive, or unsafe practices by inadequately trained health professionals. Current national registration provides a mechanism for one national Australian Drug and Poisons Legislation that could reduce inconsistencies in training across the nation. Legislation must include information to explain whether and who can amend a prescriber's order once the medication is prescribed and dispensed-also, a term to describe these medication amendments consistently.

\subsubsection{Promoting Viability of Private Practice Workforce for Diabetes}

Improving private CDEs remuneration and identifying opportunities to enable nurse practitioners to develop, implement, and evaluate Chronic Condition Management Plans in partnership with people living with diabetes can create workforce solutions to increase timely quality healthcare access and build workforce capacity. International research has established that nurse practitioners match or exceed physician colleagues in providing quality care in primary care and speciality areas [71]. However, according to Australian nurse practitioners, the current structure of the Pharmaceutical Benefits Scheme and Medicare restricts their ability to deliver a complete cycle of care [72], reducing workforce capacity.

An imperative exists to sustain timely care, as approximately $12 \%$ of Australian endocrinologists and diabetes physicians live outside major cities $[25,26]$. In contrast with Australia, the UK and USA diabetes educator workforce have infiltrated primary care $[8,73,74]$. In the UK, although $49 \%$ work in tertiary settings, $36 \%$ of diabetes nurse 
specialists are in the community, and 15\% are across both; also, they often hold non-medical prescribing endorsement [74]. Currently, 44\% of the population has some level of privately funded health cover [75]. Hence, Australia's capacity for preventative care can be increased by supporting the growth of private sector CDEs and nurse practitioners. The growth of these roles in the private sector builds workforce capacity. They can support promoting medication adherence in areas of increasing remoteness where access or adherence is low $[26,68,69]$ and can increase screening and early intervention [72].

\subsubsection{Orientating Healthcare Organisations for Capability-Based Learning}

Capability-based learning will help to increase workforce capacity in healthcare organisations and enable compassionate, high-quality healthcare. Healthcare organisations need to promote health professional autonomy to enable capability-based learning, which fosters innovation [59]. Growth and opportunity may be impeded if employers and organisations are not conducive to allowing autonomous practice on which capability-based learning is based [36]. Social conditions and arrangements in organisations need to promote autonomy and initiative because knowledge and skills can become obsolete in a rapidly evolving world, so it is essential to focus on supporting traits that make people perform [76]. Given that individual performance is influenced by self-concept and motivation, supporting autonomous practice provides more satisfaction and is more likely to promote these traits [76].

\subsection{Limitations}

Despite the proportion of disciplines sampled aligned with those from the ADEA membership survey, which suggests the sampling frame would comprise primarily nurses with one-fifth from pharmacy and allied health disciplines [8], some disciplines were not represented in the study. Only a few physiotherapists and Indigenous health practitioners were CDEs and did not meet the inclusion criteria because these professions only became eligible for CDE credentialling after 2015 [77,78]. Both groups play an integral role in the healthcare system and Indigenous health in many parts of Australia; lack of feedback was a limitation. However, further work has promoted their involvement in designing and implementing an online Capability Framework for Diabetes Care.

Other limitations were the level of information required in the first round of Delphi survey Phase one and the sheer volume of competency statements for Delphi survey Phase two ranking. The Delphi technique requires adequate time and participant commitment through the whole process to ensure the data collected are truly representative of the expert panels' opinions [79]. An inherent risk was that Delphi participants would not read each capability statement and make considered ranking decisions or that they would drop out. Researchers reviewed the length of time taken to undertake the survey and scores for similar ranking patterns in case panellists did not engage positively with the survey. The length of time it took to undertake the survey and differences in ranking within 'contentious' capabilities were quite diverse, implying participants engaged positively in the process.

\section{Conclusions}

Policy direction must be supported by the alignment of appropriate, consistent diabetes healthcare workforce training. A rigorous process of consultation and consensus developed the Capability Framework for Diabetes Care, which addresses workforce enablers identified by the Australian National Diabetes Strategy. The framework establishes diabetesrelated practices and capabilities to guide and improve diabetes health care advice and delivery in the workforce. A better diabetes-prepared health workforce might increase early detection of diabetes and complications, improve referral processes, improve care access, and reduce the risk of complications and associated healthcare costs.

Consumer engagement is supported when health messaging is consistent, and the 'Capability Framework' helps establish consistent health professional curriculum development across the nation. By promoting multidisciplinary credentialling and recognising diversity, the framework consistently supports the workforce's development to create shared under- 
standings of diabetes and evidence-based care across health professional disciplines. The framework addresses social and economic diabetes healthcare gaps by guiding remote area health professionals. Consistent terms to describe diabetes-related medicine management and prescribing and clarity about how health professionals can manage medicines once prescribed are necessary to improve healthcare for people with diabetes.

Future studies should evaluate the impact of the 'Capability Framework' if implemented nationally and whether specific capabilities are required to better tailor care to Indigenous people and the feasibility and viability of nurse practitioner-driven Chronic Condition Management Plans for people with diabetes. The findings from this study will inform diabetes policy, practice, education, and research.

Supplementary Materials: The following supporting information can be downloaded at: https: / / www.mdpi.com/article/10.3390/ijerph19021012/s1, Table S1: Expert Advisory Group members' characteristics, Table S2: Characteristics of study participants, Figure S1: Delphi survey response rate, Table S3: Ranking of practice level models by Delphi participants, Figure S2: Model threemultidisciplinary, Table S4: Stages of diabetes clinical competence associated with practice levels, Table S5: Attributes required that underpin capabilities, Table S6: Ranking and central tendencies scores for capability components for practice levels, Table S7: Minimum level of clinical competence in diabetes required by roles.

Author Contributions: Conceptualization, G.M.; methodology, G.M.; software, G.M.; validation, G.M., B.R. and J.O.; formal analysis, G.M.; secondary analysis and cross coding, B.R. and J.O.; data curation, G.M.; writing—original draft preparation, G.M.; writing—review and editing, G.M., B.R. and J.O.; supervision, B.R. and J.O.; project administration, G.M.; funding acquisition, G.M. All authors have read and agreed to the published version of the manuscript.

Funding: No research funds were received to specifically fund this research project.

Institutional Review Board Statement: The study was conducted according to the guidelines of the Declaration of Helsinki, and the study was approved by the Ethics Committee of Deakin University on 30 July 2018; reference EAG-H 102_2018. Study Protocol version 2 was used, and no changes were made.

Informed Consent Statement: Informed consent was obtained from all subjects involved in the study by either a signed consent form or implied. All participants were provided with Plain Language Statements for each stage of the study to explain the data collection method. The PLS advised that consent would be implied when they commenced the surveys. Those who attended the groups signed a consent form, and group moderators addressed the topic.

Data Availability Statement: The data presented in this study are available on request from the corresponding author. The data are not publicly available due to ethical reasons.

Acknowledgments: G.M. extends her gratitude to her primary supervisor, the late Emeritus Professor Trisha Dunning (T.D.), and associated supervisors Joan Ostaszkiewicz and Bodil Rasmussen for their ongoing wisdom and guidance throughout the PhD study. Additionally, gratitude is extended to the members of the Expert Advisory Group for their role in validating the consensus process.

Conflicts of Interest: The authors declare no conflict of interest. The funders had no role in the design of the study; in the collection, analyses, or interpretation of data; in the writing of the manuscript; or in the decision to publish the results.

\section{References}

1. Bach, L.; Ekinci, E.; Engler, D.; Gilfillan, C.; Hamblin, S.; Maclsaac, R.; Soldatos, G.; Steele, C.; Ward, G.; Wyatt, S. The high burden of inpatient diabetes mellitus: The Melbourne public hospitals diabetes inpatient audit. MJA 2014, 201, 334-338. [CrossRef] [PubMed]

2. National Health Performance Authority. Healthy Communities: Frequent GP Attenders and Their Use of Health Services in 2012-2013 (Technical Supplement). 2015. Available online: https:/ /apo.org.au/node/53739 (accessed on 1 June 2020).

3. Hendrieckx, C.; Halliday, J.; Beeney, L.; Speight, J. Diabetes and Emotional Health: A Practical Guide for Health Professionals Supporting Adults with Type 1 Diabetes or Type 2 Diabetes, 2nd ed.; National Diabetes Services Scheme (NDSS): Canberra, Australia, 2020. Available online: https:/ /www.ndss.com.au/health-professionals/resources/ (accessed on 10 November 2021). 
4. $\quad \mathrm{Ng}$, A.; Crowe, T.; Ball, K.; Rasmussen, B. Transitional needs of Australian young adults with type 1 diabetes: Mixed methods study. JMIR Diabetes 2017, 2, e29. [CrossRef] [PubMed]

5. Australian Institute of Health and Welfare. Australian Burden of Disease Study: Impact and Causes of Illness and Death in Australia 2015 and Disease Expenditure in Australia. 2019. Available online: https://www.aihw.gov.au/reports/health-welfareexpenditure/disease-expenditure-australia/contents/summary (accessed on 1 June 2020).

6. Lee, C.; Colagiuri, R.; Magliano, D.; Cameron, A.; Shaw, J.; Zimmet, P.; Colagiuri, S. The cost of diabetes in adults in Australia. Diabetes Res. Clin. Pract. 2013, 99, 385-390. [CrossRef]

7. Callander, E.J.; Corscadden, L.; Levesque, J.F. Out-of-pocket healthcare expenditure and chronic disease-do Australians forgo care because of the cost? Aust. J. Prim. Health 2017, 23, 15-22. [CrossRef] [PubMed]

8. Australian Diabetes Educators Association. Workforce in Diabetes Education. 2017. Available online: https://members.adea. com.au/resources-2/workforce-in-diabetes-education/ (accessed on 1 June 2020).

9. Australian Diabetes Educators Association. Credentialling Process. 2021. Available online: https://www.adea.com.au/ Credentialling/Initial_Credentialling (accessed on 10 December 2021).

10. Fountaine, T.; Bennett, C. Health Care Homes: Lessons from the Diabetes Care Project. MJA 2016, 205, 389-391. [CrossRef] [PubMed]

11. Queensland Health-Clinical Excellence Division. Allied Health Expanded Scope Strategy 2016-2021, Report. 2016. Available online: https:/ / clinicalexcellence.qld.gov.au/priority-areas/service-improvement/allied-health-expanded-scope-practice (accessed on 1 June 2020).

12. Department of Health. Best-Practice Examples of Chronic Disease Management in Australia. 2017. Available online: https:// www1.health.gov.au/internet/main/publishing.nsf/Content/health-care-homes-best-practice (accessed on 10 November 2021).

13. Australia Government-Department of Health. Australian National Diabetes Strategy 2021-2030, Technical Report. 2021. Available online: https:/ / www.health.gov.au/resources/publications/australian-national-diabetes-strategy-2021--2030 (accessed on 12 December 2021).

14. Rushforth, B.; McCrorie, C.; Glidewell, L.; Midgley, E.; Foy, R. Barriers to effective management of type 2 diabetes in primary care: Qualitative systematic review. Br. J. Gen. Pract. 2016, 66, e114-e127. [CrossRef] [PubMed]

15. Furler, J.; O’Neal, D.; Speight, J.; Manski-Nankervis, J.; Gorelik, A.; Holmes-Truscott, E.; Ginnivan, L.; Young, D.; Best, J.; Patterson, E.; et al. Supporting Insulin Initiation in Type 2 Diabetes in Primary Care: Results of the Stepping Up Pragmatic Cluster RCT. BMJ 2017, 356, j783. [CrossRef]

16. Hollis, M.; Glaister, K.; Lapsley, J. Do practice nurses have the knowledge to provide diabetes self-management education? Contemp. Nurse 2014, 46, 234-241. [CrossRef]

17. Ashton, H.; Wynen, M. Enhancing primary healthcare nurses' diabetes care. Nurs. N. Z. 2016, 22, 25-51.

18. Phillips, A. Practice nurses need better diabetes education to meet service and individual needs. Pract. Nurs. 2019, 30, 555-557. [CrossRef]

19. Lin, S.; Ayre, J.; Muscat, D.M. How readable are Australian multilingual diabetes patient education materials? An evaluation of national English-language source texts. Pub. Health Res. Prac. 2020, 30, 3012002. [CrossRef]

20. Australian Institute of Health Welfare. Aboriginal and Torres Strait Islander Health Performance Framework 2017 Report: Northern Territory, Cat. No. IHW 186. 2017. Available online: https://www.aihw.gov.au/reports/indigenous-health-welfare/ health-performance-framework-2017-nt/contents/table-of-contents (accessed on 3 August 2020).

21. Handtke, O.; Schilgen, B.; Mösko, M. Culturally Competent Healthcare-A Scoping Review of Strategies Implemented in Healthcare Organizations and a Model of Culturally Competent Healthcare Provision. PLoS ONE 2019, 14, e0219971. [CrossRef]

22. Caballero, A. The "A to Z" of Managing Type 2 Diabetes in Culturally Diverse Populations. Front. Endocrinol. 2018, 9 , 479. [CrossRef]

23. Burrow, S.; Ride, K. Review of diabetes among Aboriginal and Torres Strait Islander people. Aust. Indig. HealthInfoNet 2016 Available online: https:/ / healthinfonet.ecu.edu.au/healthinfonet/getContent.php?linkid=590810\&title=Review+of+diabetes+ among+Aboriginal+and+Torres+Strait+Islander+people (accessed on 1 June 2020).

24. Greenwood, M.; de Leeuw, S.; Lindsay, N. Challenges in health equity for Indigenous peoples in Canada. Lancet 2018, 391, 1645-1648. [CrossRef]

25. Department of Health. Health Workforce: The Government is Committed to Ensuring Australia has a World Class Health System, Supported by a Highly Trained, Qualified and Well Distributed Health Workforce. 2019. Available online: https: //www1.health.gov.au/internet/main/publishing.nsf/Content/Health\%20Workforce-2 (accessed on 3 August 2021).

26. National Rural Health Commissioner. National Rural Health Commissioner-Final Report, Technical Report. 2020. Available online: https:/ / www1.health.gov.au/internet/main/publishing.nsf/Content/National-Rural-Health-Commissioner-publications (accessed on 5 May 2021).

27. Gunton, J.; Cheung, N.W.; Davis, T.; Colagiuri, S.; Zoungas, S. A New Blood Glucose Management Algorithm for Type 2 Diabetes: A Position Statement of the Australian Diabetes Society. 2016. Available online: https://www.mja.com.au/journal/2014/201/1 1/new-blood-glucose-management-algorithm-type-2-diabetes-position-statement (accessed on 1 June 2020).

28. Pease, A.J.; Andrikopoulos, S.; Abraham, M.B.; Craig, M.E.; Fenton, B.; Overland, J.; Price, S.; Simmons, D.; Ross, G.P. Utilisation, access and recommendations regarding technologies for people living with type 1 diabetes. Med. J. Aust. 2021, 215, 473-478. [CrossRef] 
29. Department of Health. National Medical Workforce Strategy: Scoping Framework, Report. 2019. Available online: https:// www1.health.gov.au/internet/main/publishing.nsf/Content/Health\%20Workforce-nat-med-strategy (accessed on 1 June 2020).

30. Diabetes Australia. Australian Diabetes Map. 2021. Available online: https://www.ndss.com.au/about-the-ndss/diabetes-factsand-figures/australian-diabetes-map/ (accessed on 10 November 2021).

31. Australian Institute of Health and Welfare. Insulin Pump Use in Australia, Diabetes Series No.18. Cat. No. CVD 58. 2012. Available online: https: / / www.aihw.gov.au/getmedia/983a6c0e-55f2-465f-8bdb-d211704523a4/14454.pdf.aspx?inline=true (accessed on 1 June 2020).

32. Bhogal, H. Insulin Pump Usage-Type 1 Diabetes: 31/12/2019 and 31/12/2012, Report. 2020. Available online: https:/ /www. ndss.com.au (accessed on 8 October 2020).

33. Simmons, D.; Deakin, T.; Walsh, N.; Turner, B.; Lawrence, S.; Priest, L.; George, S.; Vanerpool, G.; McArdle, J.; Rylance, A.; et al Competency frameworks in diabetes. Diab. Med. 2015, 32, 576-584. [CrossRef] [PubMed]

34. Murfet, G. A Consensus Approach to Building Diabetes Capabilities in the Healthcare Workforce. Ph.D. Thesis, Deakin University, Burwood, Australia, 2 November 2021. Available online: https:/ / dro.deakin.edu.au/view/DU:30159402 (accessed on 2 November 2021).

35. Australian Public Service Commission. Building Capability: A Framework for Managing Learning and Development in the APS. Available online: https:/ / www.apsc.gov.au/building-capability-framework-managing-learning-and-development-aps (accessed on 10 November 2021).

36. Burcharth, A.; Præst Knudsen, M.; Søndergaard, H. The role of employee autonomy for open innovation performance. Bus. Proc. Mg. J. 2017, 23, 1245-1269. [CrossRef]

37. Brunner, M.; McGregor, D.; Keep, M.; Janssen, A.; Spallek, H.; Quinn, D.; Jones, A.; Tseris, E.; Yeung, W.; Togher, L.; et al. An eHealth capabilities framework for graduates and health professionals: Mixed-methods study. J. Med. Internet Res. 2018, 20, 1-9. [CrossRef] [PubMed]

38. Diamond, I.; Grant, R.; Feldman, B.; Pencharz, P.; Ling, S.; Moore, A.; Wales, P. Defining consensus: A systematic review recommends methodologic criteria for reporting of Delphi studies. J. Clin. Epid. 2014, 67, 401-409. [CrossRef] [PubMed]

39. Courtenay, M.; Deslandes, R.; Harries-Huntley, G.; Hodson, K.; Morris, G. Classic e-Delphi survey to provide national consensus and establish priorities with regards to the factors that promote the implementation and continued development of non-medical prescribing within health services in Wales. BMJ 2018, 8, e024161. [CrossRef] [PubMed]

40. Waggoner, J.; Carline, J.; Durning, S. Is there a consensus-on-consensus methodology? Descriptions and recommendations for future consensus research. Acad. Med. 2016, 91, 663-668. [CrossRef] [PubMed]

41. King, O.; Nancarrow, S.; Grace, S.; Borthwick, A. Diabetes educator role boundaries in Australia: A documentary analysis. J. Foot Ank. Res. 2017, 10, 28. [CrossRef]

42. Benner, P. Using the Dreyfus model of skill acquisition to describe and interpret skill acquisition and clinical judgment in nursing practice and education. Bull. Sci. Technol. Soc. 2004, 24, 188-199. [CrossRef]

43. Ericsson, K.A.; Harwell, K. Deliberate practice and proposed limits on the effects of practice on the acquisition of expert performance: Why the original definition matters and recommendations for future research. Front. Psychol. 2019, 10, 1-18. [CrossRef]

44. Robertson, P. Towards a capability approach to careers: Applying Amartya Sen's thinking to career guidance and development. Int J. Educ. Vocat. Guid. 2015, 15, 75-88. [CrossRef]

45. Kayrooz, C.; Trevitt, C. Research in Organisations and Communities: Tales from the Real World; Allen \& Unwin: Sydney, Australia, 2005.

46. Saunders, B.; Sim, J.; Kingstone, T.; Baker, S.; Waterfield, J.; Bartlam, B.; Burroughs, H.; Jinks, C. Saturation in qualitative research: Exploring its conceptualization and operationalization. Qual. Quan. 2018, 52, 1893-1907. [CrossRef] [PubMed]

47. Webb, C.; Kevern, J. Focus groups as a research method: A critique of some aspects of their use in nursing research. J. Adv. Nurs. 2001, 33, 798-805. [CrossRef]

48. Lowry, P.; Roberts, T.; Romano, N.; Cheney, P.; Hightower, R. The impact of group size and social presence on small-group communication: Does computer-mediated communication make a difference? Small Group Res. 2006, 37, 631-661. [CrossRef]

49. Erlingsson, C.; Brysiewicz, P. A hands-on guide to doing content analysis. Afr. J. Emerg. Med. 2017, 7, 93-99. [CrossRef]

50. Blair, E. A reflexive exploration of two qualitative data coding techniques. J. Methods Meas. Soc. Sci. 2015, 6, 14-29. [CrossRef]

51. Hutchings, A.; Raine, R.; Sanderson, C.; Black, N. An experimental study of determinants of the extent of disagreement within clinical guideline development groups. Qual. Saf. Health Care 2005, 14, 240-245. [CrossRef] [PubMed]

52. Noble, H.; Smith, J. Issues of validity and reliability in qualitative research. Evid.-Based Nurs. 2015, 18. [CrossRef] [PubMed]

53. Levitt, H.; Motulsky, S.; Wertz, F.; Morrow, S.; Ponterotto, J. Recommendations for designing and reviewing qualitative research in psychology: Promoting methodological integrity. Qual. Psychol. 2017, 4, 2-22. [CrossRef]

54. Naccarella, L.; Wraight, B.; Gorman, D. Is health workforce planning recognising the dynamic interplay between health literacy at an individual, organisation and system level? Aust. Health Rev. 2016, 40, 33-35. [CrossRef]

55. Australian Commission on Safety and Quality Health Care. Health Literacy. 2019. Available online: https://www. safetyandquality.gov.au/our-work/patient-and-consumer-centred-care/health-literacy (accessed on 3 August 2021).

56. Nathan, D.; Bayless, M.; Cleary, P.; Genuth, S.; Gubitosi-Klug, R.; Lachin, J.M.; Lorenzi, G.; Zinman, B.; DCCT/EDIC Research Group. Diabetes control and complications trial/epidemiology of diabetes interventions and complications study at 30 years: Advances and contributions. Diabetes 2013, 62, 3976-3986. [CrossRef] 
57. Allied Health Specialist Consultants. National Diabetes Education Review, Report. 2018. Available online: https://www.adea. com.au/contact-us/ (accessed on 1 June 2020).

58. Wheelahan, L. Rethinking skills development: Moving beyond competency-based training. In The Oxford Handbook of Skills and Training; Buchanan, J., Finegold, D., Mayhew, K., Warhurst, C., Eds.; Oxford University Press: Oxford, UK, 2017 ; pp. 636-651. Available online: https://www-oxfordhandbooks-com.ezproxyf.deakin.edu.au/view/10.1093/oxfordhb/9780199655366.001. 0001/oxfordhb-9780199655366-e-30 (accessed on 3 March 2021).

59. Robeyns, I.; Morten, F. The Capability Approach. In The Stanford Encyclopedia of Philosophy; Zalta, E., Ed.; 2020. Available online: https:/ / plato.stanford.edu/archives/win2020/entries/capability-approach/ (accessed on 3 August 2021).

60. Litchman, M.; Ryan, D.; Yehl, K.; Rinker, J.; Burke, S. Developing the 2020 Diabetes Care \& Education Specialist Competencies: A Modified Delphi Study. Diabetes Educ. 2020, 46, 378-383. [CrossRef]

61. Australian Diabetes Educators Association. The National Diabetes Nursing Education Framework. 2020. Available online: https:/ / www.adea.com.au/ndss/the-national-diabetes-nursing-education-framework/ (accessed on 3 August 2021).

62. TREND-UK. Integrated Career and Competency Framework for Adult Diabetes Nursing, 5th ed.; 2019. Available online: https: / / www.knowdiabetes.org.uk/professional/trend-uk/ (accessed on 1 June 2020).

63. United Kingdom Clinical Pharmacy Association. An Integrated Career and Competency Framework for Pharmacists in Diabetes. 2018. Available online: https:/ / www.diabetes.org.uk/professionals/training--competencies/competencies (accessed on 1 June 2020).

64. McCardle, J.; Atkin, L.; Bowen, G.; Chadwick, P.; Game, F.; Fox, M.; Pankhurst, C.; Sharman, D.; Stang, D.; Wylie, D. Capability Framework for Integrated Diabetic Lower Limb Care: A User's Guide; OmniaMed Communications Ltd.: London, UK, 2019. Available online: www.diabetesonthenet.com (accessed on 1 June 2020).

65. Aotearoa College of Diabetes Nurses. National Diabetes Nursing Knowledge and Skills Framework. 2018. Available online: https: / / www.nzno.org.nz/groups/colleges_sections/colleges/aotearoa_college_of_diabetes_nurses/education\#Framework (accessed on 1 June 2020).

66. Lozano, J.; Boni, A.; Peris, J.; Hueso, A. Competencies in Higher Education. J. Philos. Educ. 2012, 46, 132-147. [CrossRef]

67. Browne, J.; Thorpe, S.; Tunny, N.; Adams, K.; Palermo, C. A qualitative evaluation of a mentoring program for Aboriginal health workers and allied health professionals. Aust. N. Z. J. Public Health 2013, 37, 457-462. [CrossRef]

68. Langloh de Dassel, J.; Ralph, A.; Cass, A. A systematic review of adherence in Indigenous Australians: An opportunity to improve chronic condition management. Health Serv. Res. 2017, 17, 845. [CrossRef]

69. Krass, I.; Schieback, P.; Dhippayom, T. Adherence to diabetes medication: A systematic review. Diabet. Med. 2015, 32, 725-737. [CrossRef]

70. Morton, J.; Ilomäki, J.; Magliano, D.; Shaw, J. The association of socioeconomic disadvantage and remoteness with receipt of T2D medications in Australia: A nationwide registry study. Diabetologia 2020. [CrossRef]

71. Carranza, A.; Munoz, P.; Nash, A. Comparing quality of care in medical specialties between nurse practitioners and physicians. J. Am. Assoc. Nurse Pract. 2020, 33, 184-193. [CrossRef]

72. Currie, J.; Chiarella, M.; Buckley, T. Privately practising nurse practitioners' provision of care subsidised through the Medicare Benefits Schedule and the Pharmaceutical Benefits Scheme in Australia: Results from a national survey. Aust. Health Rev. 2019, 43, 55-61. [CrossRef] [PubMed]

73. Rinker, J.; Dickinson, J.; Litchman, M.; Williams, A.; Kolb, L.; Cox, C.; Lipman, R. The 2017 diabetes educator and the diabetes self-management education national practice survey. Diabetes Educ. 2018, 44, 260-268. [CrossRef] [PubMed]

74. Hicks, D.; James, J. A diabetes specialist nurse audit within NHS England. Pract. Diabetes 2020, 37, 173-176. [CrossRef]

75. Australian Institute of Health and Welfare. Private Health Insurance. 2020. Available online: https://www.aihw.gov.au/reports/ australia-health/private-health-insurance (accessed on 10 November 2021).

76. Rybnicek, R.; Bergner, S.; Gutschelhofer, A. How individual needs influence motivation effects: A neuroscientific study on McClelland's need theory. Rev. Manag. Sci 2019, 13, 443-482. [CrossRef]

77. Australian Diabetes Educators Association. Annual Report 2014-2015. 2015. Available online: https://www.adea.com.au/wpcontent/uploads /2016/09/Annual-Report-2015-final-web12082015.pdf (accessed on 1 June 2020).

78. Australian Diabetes Educators Association. National Core Competencies for Aboriginal and/or Torres Strait Islander Diabetes Health Workers and Diabetes Health Practitioners. 2018. Available online: https://www.adea.com.au/resources/standardsposition-statements-and-other-resources/standards / (accessed on 1 June 2020).

79. Flanagan, T.; Ashmore, R.; Banks, D.; MacInnes, D. The Delphi method: Methodological issues arising from a study examining factors influencing the publication or non-publication of mental health nursing research. Ment. Health Rev. J. 2016, 21, 85-94. [CrossRef] 